\title{
Cutaneous Melanoma cN3 TNM Finding v8
}

National Cancer Institute

\section{Source}

National Cancer Institute. Cutaneous Melanoma cN3 TNM Finding v8. NCI Thesaurus. Code C136918.

Cutaneous melanoma with four or more tumor-involved nodes or in-transit satellite, and/or microsatellite metastases with two or more tumor-involved nodes, or any number of matted nodes without or with in-transit, satellite, and/or microsatellite metastases. (from AJCC 8th Ed.) 